\title{
Investigating Structural Cracks for Infrastructure: Case Study of Anonymous Hospital, in Zimbabwe
}

\author{
Tinashe Matora ${ }^{1}$, Samson Shumba ${ }^{2}$, Tawanda Mushiri ${ }^{3}$, Kudzie Musiwa $^{4}$, \\ Dakarai Taaka $^{5}$, Stewart Mhizha ${ }^{6}$ and Michael James Tumbare ${ }^{7}$ \\ \{tinashe.matora.tm@gmail.com ${ }^{1}$, sshumba08@gmail.com², tawandamushiri@gmail.com ${ }^{3}$ \} \\ Faculty of Engineering, University of Zimbabwe, P.O Box MP167 Mount Pleasant, Harare, \\ Zimbabwe
}

\begin{abstract}
The main objective of the research was to investigate the structural cracks for infrastructure at the anonymous Hospital in Zimbabwe and recommend the appropriate engineering solutions to the structural problems. Desk studies, geotechnical and materials investigations and investigations of the structural designs for the existing infrastructure was conducted. Geotechnical tests included sieve analysis, soil indicator, shear strength, direct cone penetrometer, chemical dispersive and California bearing ratio tests. Most of the cracks were structural cracks. The foundation depth was determined as $1.5 \mathrm{~m}$ for a bearing capacity more than $100 \mathrm{kPa}$. The causes of cracks included use of substandard bricks and construction materials, thick mortar and inadequate foundation depth. The dispersive test also proved that the soils are sodic in nature. It is recommended to use reinforced strip foundations and deep foundations when constructing infrastructure at the site. Heavy duty concrete foundation underpinning is recommended for the existing buildings.
\end{abstract}

Keywords: Geotechnical investigations, Structural cracks, Bearing capacity, Sodic soils, Foundation underpinning.

\section{Introduction}

\subsection{Background to the Study}

Structural failures are part of engineering that deals with the ability of a structure to withstand various forces subjected to the unit. Structural failure is the loss of the load carrying capacity of a component resulting in visible fracture or excessive deformation. The science of interrogating structural failures is not new but is one that has not been fairly researched and practiced in Zimbabwe and the region. This paper seeks to investigate structural problems for an anonymous hospital in Zimbabwe and takes a step in addressing section 7.3 of the Zimbabwe Agenda for Sustainable Socio-Economic Transformation (Zim-ASSET). Infrastructure in the area is facing an uncertain future as the buildings are failing and some are at risk of collapse, therefore there is need to provide remedies to the problem and improve the residents' living conditions. The place under study is located mainly in the mid-altitude areas of the country and is characterized by annual rainfall of $500-750 \mathrm{~mm}$, mid-season dry spells and high temperatures, the bedrock/parent materials are Karoo sandstone/colluviums and the 
soil is characterized as fine sandy and sodic soils [1]. The erosion hazard for the region is said to be variable having low water holding capacity. The anonymous Hospital is in a small community which supports the locals with provisions such as primary and a secondary school, a hospital which is the biggest in the place under study catering for transfers from the nearby ZIMPLATS mine. Figure 1 shows a map of the study area. Buildings in the anonymous Hospital are showing signs of failure, both the old and the new ones.

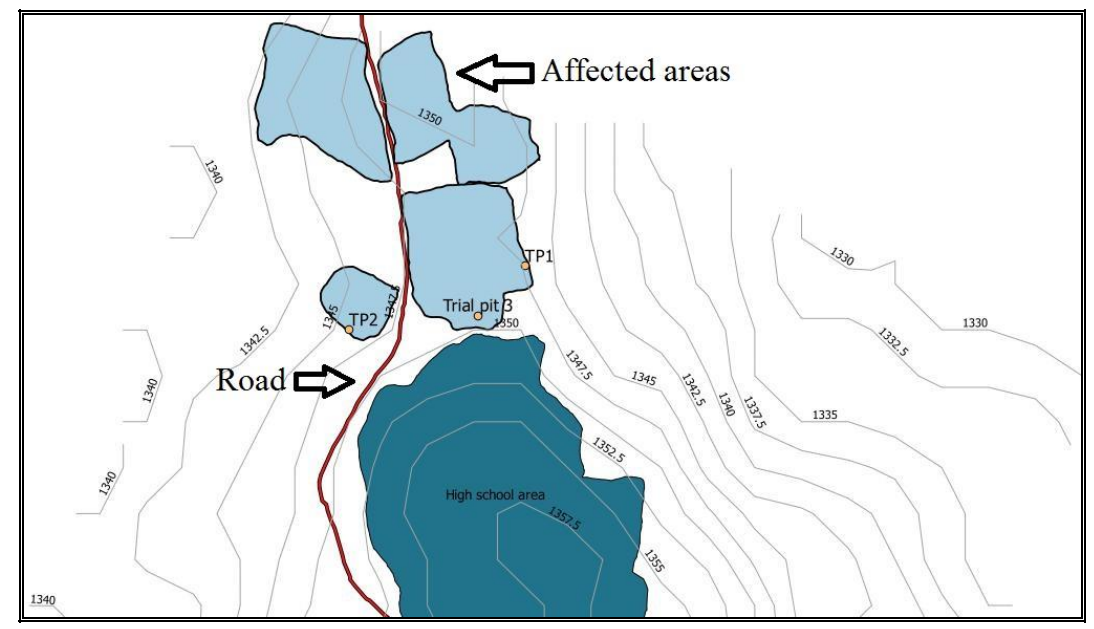

Fig. 1. Map of the Study Area

\subsubsection{Causes of Cracks}

Cracking due to reinforcement in bed joint reinforcement over openings in masonry facades generates increasing retrofitting needs [2]. The crack frequency can be correlated to the orientation of the walls and height above ground level [2], corrosion is affected by moisture content and temperature in the surrounding of the building. Most building cracks are non-structural and these include shrinkage cracks and joint cracks, surface cracks on floors caused by improper curing [3]. Plaster thickness, corrosion of reinforcement and inadequate bonding are the other causes of cracks [3]. Some of the geologically derived materials that could lead to building failure and cracks include soluble rocks, shrinkage and swelling of clay, groundwater fluctuations, soil geochemistry ( $\mathrm{pH}$, sulphate, and chloride), peat and unconsolidated recent deposits [4]. According to studies [4] soil acidity dissolves the cement of the foundation causing cracks and the solution is to add lime. Some buildings have developed cracks 20-40 cm wide and of varying lengths as shown in Figure 2 and Figure 3, then there are some which are showing signs of settlement. 


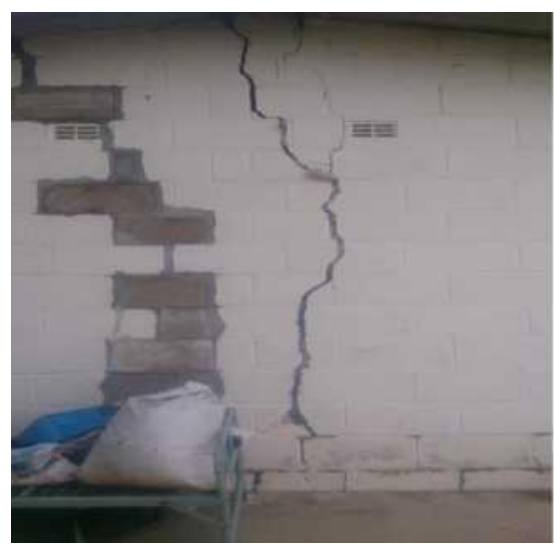

Fig. 2. A jagged vertical crack on the wall of a building

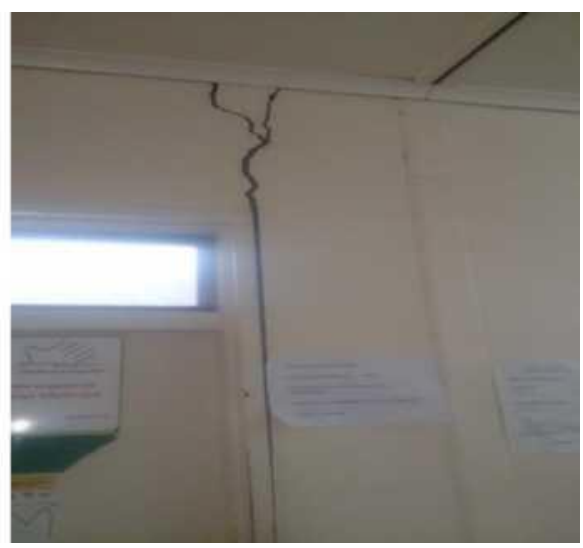

Fig. 3. Vertical crack on another building

\subsubsection{Current Repair Strategies}

Advanced Composite Materials (ACM) in the form of fibre reinforced polymer (FRP) can be applied to strengthen reinforced concrete structures and ageing infrastructure where cracking is caused by corrosion of steel reinforcement [5]. The foundation can be inadequate to fully support the imposed loads [6] and this result in an increase in foundation settlement/differential settlement which may cause structure movement [7]. Wall cracks result from excessive stress on the masonry wall. Studies [8] show the methods of crack repair depend on the width, depth and nature of cracks. The methods vary from no repair to compatible patch repairs, chemical injections and use of reinforcement to close the crack opening. Dry packing, drilling and plugging, chemical grouts, hydraulic cement grouting, stitching (drilling holes on both sides of the crack and anchoring U-shaped metal staples with short legs across the crack). [8]. Other methods of solving foundation problems is underpinning and its various forms [9].

\subsubsection{Gulley Problems}

Soil erosion is widely recognised as a major environmental problem affecting many parts of the world [10]. Soil erosion develops into sheet erosion, rill erosion and gully erosion which is the most advanced stage of soil erosion [11]. Gullies develop because of a decrease in soil surface resistance to erosion or an increase in the erosive forces acting on the land surface [12]. Presence of gullies in many areas is a threat to the economic way of life of a community and also infrastructure [13].

\subsection{Problem Statement}

Infrastructure at the place under study is showing signs of failure due to the development of cracks and other defects. This has affected the development in the area since the causes of the current problems and the remedies have not been identified. 


\subsection{Research Objectives}

The main objective of the research was to investigate the structural cracks for infrastructure at the anonymous Hospital in the place under study, in Zimbabwe and recommend the appropriate engineering solutions to the structural problems. The specific objectives involved conducting desk studies and geotechnical and materials investigations to obtain the relevant data required for the design solutions. The work also involved investigating the structural designs for the existing infrastructure and producing the construction schedule.

\section{Materials and Methods}

Figure 4 and 5 show the procedure carried out for conducting geotechnical investigations and chemical tests.

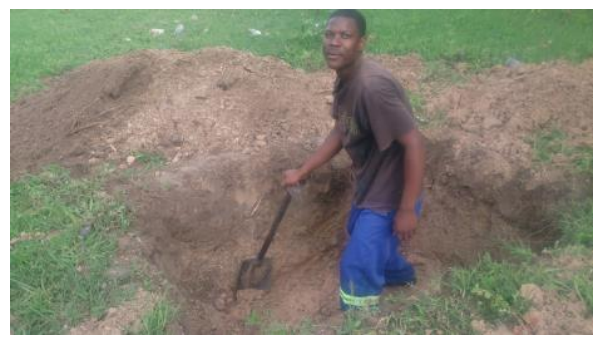

Fig. 4. Digging trial pits for geotechnical tests.

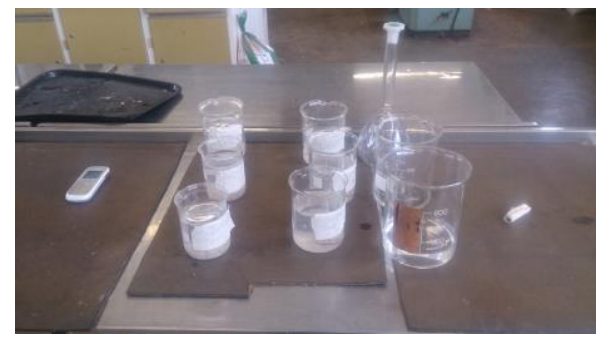

Fig. 5. Laboratory testing in progress

Geotechnical analysis needs to be conducted in order to determine the appropriate design approach and minimise potential impact on the adjacent buildings, analytical methods and numerical simulations are used [14], [15]. Calculation of the live loads and quality control of materials uniformity [16] and measurement of cracks is done [3]. The process of data collection was done over a period of one week from the 8 th -15 th of January 2017. A reconnaissance survey was undertaken in order to familiarize with the area, identifying the types, extent and severity of the structural damage that buildings in the Mission area are suffering. A qualitative assessment was done; conducting interviews with the locals so as to get an insight of the views of the locals on what is happening in their area. Geotechnical investigations were then conducted and the task included excavation of trial test pits, collecting soil samples, conducting in-situ tests such as the direct cone penetrometer test (dcp) and conducting laboratory tests on the samples collected. Figure 4 shows excavation of the trial pit.

\section{Research Findings}

\subsection{Results from Fieldwork}




\subsubsection{Causes of Building Cracks}

The vertical wall varied from $1 \mathrm{~m}$ to $5 \mathrm{~m}$ in length and $0.5 \mathrm{~mm}$ to $45 \mathrm{~mm}$ in width. Externally applied loads cause horizontal cracks. Settlement problems and heaving cause vertical cracks which are wider at the top and bottom. Table 1 shows the results obtained during fieldwork at the anonymous Hospital. The design limits according to BS5628 [16].

Table 1. Crack length and width

\begin{tabular}{cccc}
\hline Location & Length $(\mathbf{m m})$ & Width $(\mathbf{m m})$ & Design Limits \\
\hline B1 (Laboratory-TP3) & $1000-2000$ & $15-35$ & $<15 \mathrm{~mm}$ \\
B2 (Washrooms-TP1) & $2100-3000$ & $20-40$ & $<15 \mathrm{~mm}$ \\
B3 (Staff House-TP2) & $500-3000$ & $20-45$ & $<15 \mathrm{~mm}$ \\
B4 (Staff House) & 3000 & $30-42$ & $<15 \mathrm{~mm}$ \\
B5 (Staff House) & $1000-2500$ & $15-30$ & $<15 \mathrm{~mm}$ \\
\hline
\end{tabular}

The crack widths exceeded the design limits so these are structural cracks which need to be repaired urgently, from [17] these are more than $25 \mathrm{~mm}$. Geotechnical and analytical approaches were employed in the collection of the data.

\subsubsection{Results from key informant interviews}

The building infrastructure is more than 30 years old. The recently constructed houses are less than 10 years old. The cracks were observed long back but they were not as severe as they are now. The latest building to be detected with cracks was the laboratory block completed in 2015 and it has since been condemned. The hospital technical personnel attribute the cracking of infrastructure to presence of weak soil, substandard materials and poor workmanship, the age of the buildings, the gullies and the blasting vibrations from Zimplats Mine.

\subsubsection{Construction Materials}

The construction materials used when the hospital and staff housing were built could not be accessed as this happened in the 1980's. However, for the recently constructed hospital laboratory a few bricks were still available. Other materials used were no longer available and only in situ analysis would be feasible. Figure 6 shows the common farm brick used to construct the infrastructure.
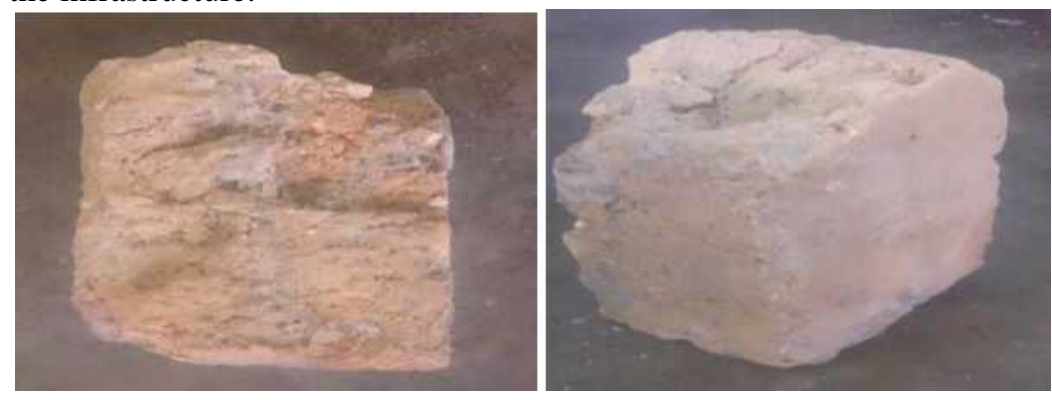

Fig. 6. Common Farm Brick collected from site shows weak bearing capacity and would crumble easily. 


\subsubsection{Gullies}

The existence of gullies in the vicinity of the mission area was a popular response as well. However, after mapping the area to determine the location of the gully in relation to the affected buildings, the gullies' development could not have contributed to failure of the structures.

\subsection{Results from Laboratory Work}

\subsubsection{Plasticity Tests (Indicator Tests)}

This is a summary of the Atterberg limits results. From the results summarised in Table 2 the soil in the vicinity of Trial Pit 1 (TP1) is predominantly sandy to sodic. The soil sample could not be moulded in order to perform the test and also samples which were tested for shrinkage showed no sign of shrinkage for the different moisture contents. The soil in the vicinity of Trial Pit 2 is classified as Clay of Intermediate Plasticity, and that in the vicinity of Trial Pit 3 is classified as Clay of Low Plasticity. The results are shown in Table 2.

Table 2. Summary of Plasticity Tests

\begin{tabular}{lcccc}
\hline Location & $\begin{array}{c}\text { Liquid Limit } \\
\left(\mathbf{W}_{\mathbf{L}}\right)\end{array}$ & Plastic Limit $\left(\mathbf{W}_{\mathbf{L}}\right)$ & $\begin{array}{c}\text { Plasticity Index } \\
(\mathbf{I P})\end{array}$ & $\begin{array}{c}\text { Linear } \\
\text { Shrinkage } \\
(\mathbf{L S})\end{array}$ \\
\hline TP1 @ $1.5 \mathrm{~m}$ & - & - & - & 0 \\
TP2 @ $2.0 \mathrm{~m}$ & $40 \%$ & $19 \%$ & $21 \%$ & $9 \%$ \\
TP3 @ FL & $30 \%$ & $17 \%$ & $13 \%$ & $7 \%$
\end{tabular}

\subsubsection{Shear Box (Direct Shear) Test Results}

The results of the shear strength parameters for the soil are shown in Table 3.

Table 3. Shear strength parameters for the soil samples from the trial pits

\begin{tabular}{rrrc}
\hline Location & & Cohesion $\left(\mathbf{k N} / \mathbf{m}^{2}\right)$ & Angle of Friction (degrees) \\
\hline TP1 & 13.210 & 23.6 \\
TP2 & 29.240 & 11.7 \\
TP3 & 12.328 & 3.6 \\
\hline
\end{tabular}

\subsubsection{Sieve (Particle Size) Analysis Test Results}

Generally, the soils are sandy soils, there are a few areas with the existence of rocky material but the rock particles are mostly sedimentary rocks. Table 4 shows the summary of sieve analysis test results on the soil samples.

Table 4. Summary of the Sieve Analysis Test Results

\begin{tabular}{ccc}
\hline Location & Description & Comments \\
\hline TP1 & Poorly graded sandy soil & Sample predominantly of the same size (sand) \\
TP2 & Poorly graded sandy soil & $\mathrm{C}_{\mathrm{U}}<6$ and $1<\mathrm{C}_{\mathrm{C}}<3$ shows that the soil is
\end{tabular}


poorly graded sand

\subsubsection{Bearing Capacity Test (DCP and CBR)}

A summary of the bearing capacity and California bearing ratios is shown in Table 5. The soil has adequate bearing capacity and the minimum foundation depth is $1.5 \mathrm{~m}$.

Table 5. Summary of the bearing capacity and California Bearing Ratio Test Results

\begin{tabular}{cccc}
\hline Trial Pit & $\begin{array}{c}\text { Ideal depth below ground } \\
\text { level }(\mathbf{m m})\end{array}$ & $\begin{array}{c}\text { Bearing Capacity } \\
(\mathbf{k P a})\end{array}$ & Average \% CBR \\
\hline 1 & 2000 & $200-300$ & 25 \\
2 & 2500 & $300-500$ & 35 \\
3 & 1500 & $100-180$ & 15 \\
\hline
\end{tabular}

\section{Structural Design Work}

\subsection{Structural Engineering Design}

Checking for structural failure is a complicated science that differs from one project to the next. The anonymous site was subject to depth forensic investigations that resulted in scientific analysis and conclusions to try and solve the challenges of structural cracks. The components were considered separately and analyzed for loads and bearing capacity. A quick estimate of the allowable bearing capacities was computed using equation 1: [17].

$$
Q_{\text {allowable }}=\frac{c N_{c}+q_{c} N_{q}+0.5 y B N_{Y}}{F}
$$

Where the Factor of safety against bearing capacity $F$ is between 2 and 3 and $q_{0}{ }^{\prime}$ is the effective burden pressure, $¥$ is the unit weight of the soil, B is the width of the foundation, $c$ is the cohesion and $\mathrm{N}_{\mathrm{c}}, \mathrm{N}_{\mathrm{q}}$ and $\mathrm{N}_{\gamma}$ represent the shallow bearing capacity factors. The value of allowable pressure was computed and compared to the DCP values. The flexural strength of the masonry was also computed and analyzed with samples of bricks that had parameters close to the one discovered on site. The overall flexural capacity of a panel depends on the dimensions, orthogonal strength ratio and support conditions [17]. The ultimate flexural strength of a cracked wall spanning vertically was checked for various building units using the equation 2 .

$$
M_{a d m}=\frac{\gamma_{W} t^{2} h}{2 F}
$$

The chemical composition and properties of the soil were considered using the dispersive test and other various geotechnical test highlighted above. 


\subsection{Repair Strategies}

From [19] for cracks up to $1 \mathrm{~mm}$ the damage is only experienced to the wall finishes and the treatment can be done by normal decoration. Cracks with a width from 1 to $5 \mathrm{~mm}$ can easily be filled. Cracks from $5-15 \mathrm{~mm}$ require some opening up and can be patched by a mason, some bricks need to be replaced. For cracks from 15-25 mm this is extensive damage and requires breaking out and replacing sections of the wall especially over doors and windows. The walls will be leaning or bulging. For cracks more than $25 \mathrm{~mm}$ this is structural damage that requires a major repair job involving partial or complete rebuilding. If cracking on concrete is due to drying shrinkage the crack will stabilize, if due to foundation settlement the settlement problem must be corrected [9]. For cracks less than $1 \mathrm{~mm}$ bonding by injection of epoxy is recommended. Routing and sealing of cracks can be used whereby the crack is enlarged along its exposed face and a joint sealer is used to fill and seal the crack [9]. The other methods recommended include near-surface reinforcing and pinning, additional reinforcement, drilling and plugging, polymer impregnation, grouting and crack arrest [9].

For simple structures presented in this paper it would be inappropriate to use piled underpinning methods or pumping grout or any other polymeric chemicals to repair the buildings as it would be expensive. The solution provided was compared to the cost of demolition and reconstructing and the design concept was made to suit the facet of the project. Cost is a major contributor to the decision and solution provided. Expertise and technical knowhow was also considered.

\subsection{Cost of Repairs}

The costs for repairing the existing structures is valued at US\$456 800.00 including materials and construction costs. The costs are calculated for the laboratory, one block (including the administration, wards, outpatient), the mortuary, the doctor's residence, the former nurse training building and about five other staff accommodation units. As calculated in our bill of quantity (Not attached in this paper). The repair works would take up to 100 working days according to the designed program of works.

\section{Conclusions and Recommendations}

\subsection{Conclusions}

Structural failures for the site in question were investigated and it was noted that:

- The bricks utilised for the construction are of poor flexural strength and the brickwork was not bonded creating fault line vertical cracks

- The soils are sodic in nature and resulted in collapse as the sodium component dissolved with fresh water and subsequent erosion below foundations.

- The Mine company blast could not be directly sidelined though vibrations can be the reason for the increased crack width and effect of topography on foundation erosion.

- The bearing capacity of the soils in some cases was not adequate to carry the load.

Currently there has not been any repair strategies that have been put in place. 


\subsection{Recommendations}

It is recommended to use deep foundations, reinforced strip foundations, allowing for weep holes where terrain is highly differential, foundation underpinning and stabilising the base foundation when constructing buildings at the Anonymous hospital. It is also recommended that the structures with the failures recorded in this paper be treated with caution and repaired as some of the structural failures are far beyond serviceability failures. Using the findings from this paper, such as the repair strategies, similar studies can be done on other buildings experiencing structural failures.

\section{Acknowledgements}

Faculty of Engineering, University of Zimbabwe; Anonymous Company

Environmental Management Agency (EMA), Zimbabwe

KST Consultants, Zimbabwe

\section{References}

[1] Frith, C.R. and Whitlow, R.: Patterns of Gullying in Zimbabwe. GeoJournal: Soil Erosion and Host Materials in Africa 23(01): 59-67 (1991)

[2] Molnar, M. and Ivanov, O.L.: Clay brick masonry facades with cracks caused by corroding bed joint reinforcement. Findings from field survey and laboratory study; SciDirect Construction and Building Materials 125 (2016) 775-783.

www.elsevier.com/locate/conbuildmat (2016)

[3] Suffian A., 2013. Some Common Maintenance Problems and Building Defects: Our Experiences. The 2nd International Conference on Rehabilitation and Maintenance in Civil Engineering (ICRMCE). Procedia Eng. 54101 -108. Elsevier. SciVerse ScienceDirect, www.sciencedirect.com, doi:10.1016/j.proeng.2013.03.009 (2013)

[4] Amadi A.N, Eze C.J, Igwe C.O, Okunlola I.A. and Okoye N.O.: Architect's and Geologist's View on the Causes of Building Failures in Nigeria. Modern Applied Science, Vol. 6 No. 6, 2012. Canadian Centre of ScienceandEducation.ISSN1913-1844. http://dx.doi.org/10.5539/mas.v6n6p31 (2012)

[5] Mohamed A. M., Abdel-Hady, H and Amr, A.: Use of FRP in Egypt, Research Overview and Applications. The 2nd International Conference on Rehabilitation and Maintenance in Civil Engineering (ICRMCE), SciVerse ScienceDirect, Procedia Engineering 54 (2013) 2-21. www.elsevier.com/locate/procedia (2013)

[6] Sholihin A, Mukahar M. and M. Sukiman.: Investigation on Wall Crack Damage and Its Proposed Repair Method. The 2nd International Conference on Rehabilitation and Maintenance in Civil Engineering (ICRMCE). Procedia Eng. 54 (2013) 165-175. Elsevier. SciVerse ScienceDirect, www.sciencedirect.com, doi:10.1016/j.proeng.2013.03.016 (2013)

[7] Gebregziabhier T.T., 2008. Durability Problems of 20th Century Reinforced Concrete, Heritage Structures and their Restoration, Paper, July 2008, Technical University of Catalonia, Barcelona (2008)

[8] ACI 1224.IR-07.: Causes, Evaluation and Repair of Cracks in Concrete Structures. American Concrete Institute. www.concrete, org (2007)

[9] BRE Digest 251. Assessing cracks in houses. https://www.bre.co.uk. Accessed on 3 February 2017 (2017)

[10] Lötter, L., Stronkhorst, L.D., Smith, H., J.: Sustainable Land Management Practices of South Africa, Agricultural Research Council - Institute for Soil, Climate and Water, Pretoria (2009) 
[11] Pimentel, D., Harvey, C., Resosudarmo, P., Sinclair, K., Kurz, D., McNair, M., Crist, S., Shpritz, L., Fitton, L., Saffouri, R., Blair, R.: Environmental costs of soil erosion and conservation benefits (1995)

[12] Danladi, A., Ray, H.H.: Socio-economic effect of gully erosion on land use in Gombe Metropolis-Nigeria. Journal of Geographic and Regional Planning, 7(5): 9 (2014)

[13] Jahantigh, M., Pessarakli, M.: Causes and Effects of gully erosion on Agricultural Lands and the Environment. Communications in Soil Science and Plant Analysis: 8 (2011)

[14] Chepurnova A.: Assessing the influence of jet grouting underpinning on the nearby buildings. Journal of Rock Mechanics and Geotechnical Engineering 6 (2014) 105-112. www.rockgeoteck.org. Elsevier, http://dx.doi.org/10.1016/j.jrmge.2014.01.005 (2014)

[15] Burland J.: The assessment of the risk of damage to buildings due to tunneling and excavations. https://www.eteg.upc.edu/docencia/aulapaymacotas/edificis/ponencies/burland:1995 (2011

[16] BS5628.: British Standards Institute; Code of practice for the use of masonry-Part 1: Structural use of unreinforced masonry. BSI 389 Chiswick High Road London.W4 4AL (1996)

[17] BS8110-1., 1997. Structural use of Concrete Part 1, British Standards Institution, London (1997) 